\title{
Optimized design of collector topology for offshore wind farm based on ant colony optimization with multiple travelling salesman problem
}

\author{
Ramu SRIKAKULAPU ${ }^{1}$ [D, Vinatha $\mathbf{U}^{1}$
}

\begin{abstract}
A layout of the offshore wind farm (OSWF) plays a vital role in its capital cost of installation. One of the major contributions in the installation cost is electrical collector system (ECS). ECS includes: submarine cables, number of wind turbines (WTs), offshore platforms etc. By considering the above mentioned problem having an optimized design of OSWF provides the better feasibility in terms of economic considerations. This paper explains the methodology for optimized designing of ECS. The proposed methodology is based on combined elitist ant colony optimization and multiple travelling salesman problem. The objective is to minimize the length of submarine cable connected between WTs and to minimize the wake loss in the wind farm in order to reduce the cost of cable and cable power loss. The methodology is applied on North Hoyle and Horns Rev OSWFs connected with 30 and 80 WTs respectively and the results are presented.
\end{abstract}

Keywords Ant colony optimization, Offshore wind farm, Multiple travelling salesman problem, Wake effect, Wake loss

CrossCheck date: 7 December 2017

Received: 10 October 2016/Accepted: 7 December 2017/Published online: 2 March 2018

(C) The Author(s) 2018. This article is an open access publication

$\bowtie$ Ramu SRIKAKULAPU

ram2314u@gmail.com

Vinatha $\mathrm{U}$

u_vinatha@yahoo.co.in

1 Department of Electrical and Electronics Engineering, National Institute of Technology Karnataka, Surathkal, Mangalore 575025, India

\section{Introduction}

In last two decades, the utilization of wind energy was elevated to an appreciable level. Wind energy is a solution for drawbacks of traditional energy sources. Based on the placement of wind turbine (WT) the wind farms are classified into two types. They are offshore and onshore. The offshore wind farms (OSWFs) are gaining importance over onshore wind farms because of: (1) no land requirement and space restrictions [1]; (2) higher installation capacity; (3) availability of strong wind flow; (4) no limitation for higher rated wind turbine installations. The OSWFs are designed in clusters and each consisting of tens to hundreds of WTs. The OSWF contains WTs, transformers, offshore platforms, and submarine cables etc. Collector topology plays an important role in connecting these turbines to the hub. In order to increase the rating of OSWFs either of the following is to be carried out.

1) Increase in number of WTs, consequently increases the length of submarine cable connected between the WTs and collector hub.

2) It requires larger size collector system and higher rating transformers.

Due to the above reasons, the capital cost of OSWF will be higher. In addition, OSWF has higher maintenance and outage cost due to a critical operational environment and low accessibility [2]. Reduction in cost can be achieved by the optimized design of wind farm in terms of collector system and cable layout. In [3, 4], authors have used geometric programming and genetic algorithm (GA) respectively for optimization of the layout. In [5, 6], combination of improved GA and multiple travelling salesmen problem (MTSP) is proposed for the same context. GA approach discussed in [7] addresses the problem 
of the optimal micro siting of WTs. In [8], Bender's decomposition strategy, scenario aggregation technique and progressive contingency incorporation techniques are applied to improve the computation time of optimal design. The fuzzy C-mean (FCM) with binary integer programming method is applied to automatically allocate the WTs to nearest substations [9]. Minimum spanning tree (MST) method was used for the design of an optimal electrical layout in $[9,10]$. Finally, a hybrid AC-DC OSWF topology with mixed integer nonlinear programming method is used to obtain the optimal performances like cost minimization and reduction in a number of AC-DC power converters [1].

The particle swarm optimization (PSO) [11, 12] and mixed integer PSO [13] techniques are adopted to optimize the wind farm layout in terms of optimal placement allocation of WTs. Clarke and Wright savings heuristic method with vehicle routing [14], ant colony optimization (ACO) with GA [15] and capacitated MST [16] were implemented for the optimization of inter-array cable routing between WTs in OSWFs. A self-adaptive allocation (SAA) method was proposed to place the substations and WTs in OSWF [17]. The SAA method is based on a combination of PSO and FCM clustering algorithm. In [18], the combination of adaptive PSO and MST methods were applied to optimize the OSWF and compared the optimized layout by MST, Dynamic MST, and APSO-MST. Optimized power dispatch method and PSO are employed to minimize the levelized production cost value and design optimally the regular shaped offshore wind farm respectively [19]. A DMST method on the irregular shaped wind farm is applied in [20].

The wake effect is an important factor in wind farm design. A higher rating of WTs gets more affected by the wake. In case of larger OSWFs, wake effect decreases the total power generation of the wind farm. Wake is the variation of wind speed from weaker to strengthen point behind the WT. The downstream WTs experience the wake effect. The wake effect depends on the allocation of WT in the wind farm. If the distance between the consequent WTs is less, the effect of wake on downstream side WT will be more. In [21], authors have calculated the power loss in OSWF considering turbulence intensity and atmospheric stability. These two parameters strongly affect the wake formation. Wake models are proposed to analyze the wake effects in [22]. Those are Jensen model by N.O.Jensen, Larsen model by G.C. Larsen, Storpark analytical model by Frandsen and Ainslie Model by J.F.Ainslie. Larsen wake model is chosen in this paper to optimize the OSWF.

In Section 2, ACO and elitist ACO with MTSP approach are explained. Section 3 explains the model of OSWF. It gives a detailed explanation of wake model. Section 4 elucidates the problem formulation. Section 5 presents the case study and results. Finally, Section 6 gives the conclusion.

\section{Ant colony optimization}

ACO is a biological motivation of ants to locate the shortest path between the nest and food. It is a population based search technique. In the process of searching food, ants release a chemical (pheromone) on the ground in the path. Ants are choosing the random path from a nest and decide the shortest path based on strength of pheromone. The strength of pheromone decays fast with time; hence the length of the path is less if the strength of pheromone in a particular path is more. Remaining ants follow the path almost blindly and hardly use vision. They decide the path by the probability to follow the optimal strength of pheromone and the remaining ants will follow it. The mathematical explanation of ACO is described as follows [23]:

At the starting of the food search process, the strength of pheromone $\tau_{i j}$ is constant.

$\tau_{i j}=1 \quad \forall(i, j) \in A$

where $A$ is the set of travel points of ant.

The probability rule to choose the next point $j$ of ant $k$ is given in (2).

$p_{i j}^{k}=\frac{\tau_{i j}^{\alpha}}{\sum_{l \in N_{i}^{k}} \tau_{i j}^{\alpha}}$

where $N_{i}^{k}$ is the region of ant $k$ when it in $i^{\text {th }}$ point.

Update the pheromone value as follows:

$\tau_{i j}=(1-\rho) \tau_{i j}+\Delta \tau^{k}$

where $\Delta \tau^{k}$ is specified in (4).

$\Delta \tau^{k}=1 / L_{k}$

where $L_{k}$ is the length of ant $k$ path.

\subsection{Multiple travelling salesmen problem}

In MTSP, $n$ numbers of cities are allotted to $m$ number of salesmen. The main aim of the method is that multiple salesmen have to travel the specified cities. First, the salesmen start the tour from any city and travel to set of cities without arriving the starting point in between. The conditions are: (1) each salesman has to take different route; (2) they have to touch every specified city without fail; (3) if a salesman has covered a particular city then other salesmen should not travel to that city; (4) in each route, salesmen has to travel city only once in their tour [23]. 


\subsection{Elitist ACO with MTSP}

In combined elitist ACO and MTSP, the number of ants is chosen by a number of cities. Every ant randomly chooses the city and makes individual tour from an initial city. Depending on the probability rule, ants will select next city to go. Probability rule is a function of the distance between the cities and strength of pheromone on the connecting cities.

The elitist strategy for ACO with MTSP is explained as follows:

An initial value of pheromone is constant and it is $\tau_{i j}(0)=1$.

Visibility $\eta_{i j}$ is routing the desirable nearest city.

$\eta_{i j}=1 / d_{i j}$

where $d_{i j}$ is the distance between the city $i$ to $j$.

Probability rule [24] is given in below.

$p_{i j}=\frac{\left[\tau_{i j}\right]^{\alpha}\left[\eta_{i j}\right]^{\beta}}{\sum_{x \in \text { allowed }}\left[\tau_{i j}\right]^{\alpha}\left[\eta_{i j}\right]^{\beta}}$

where $p_{i j}$ is the probability value to select the next city; $\alpha$ is the pheromone trail constant; $\beta$ is the guide investigation constant; $\tau_{i j}$ is the pheromone strength of path between city $i$ to $j$.

In (6), $\sum_{x \in \text { allowed }}$ adds the untouched cities in a tour.

Update the pheromone trails using (7).

$\tau_{i j}=(1-\rho) \tau_{i j}+\sum_{k=1}^{m} \Delta \tau_{i j}^{k}+e \Delta \tau_{i j}^{b s}$

where $\rho$ is evaporation rate of pheromone ( 0 to 1$) ; \Delta \tau_{i j}{ }^{k}$ is the updated pheromone value of $k^{\text {th }}$ ant; $\Delta \tau_{i j}{ }^{b s}$ is the pheromone value of the best-so-far; $e$ is the weight parameter of the best-so-for tour; $m$ is the numbers of ants.

In (7), $\Delta \tau_{i j}^{k}=Q / L_{k}$ if $k^{\text {th }}$ ant tour in $(i, j)$, otherwise 0. $\Delta \tau_{i j}^{b s}=Q / L_{b s}$ if $k^{\text {th }}$ ant tour best-so-far in $(i, j)$, otherwise 0. $L_{b s}$ is the length of tour best-so-far, $L_{0}$ is the initial tour length, $Q$ is the amount of raise pheromone coefficient.

\subsection{Elitist ACO with MTSP realization}

The elitist ACO with MTSP algorithm is explained by flow chart as shown in Fig. 1.

The process of elitist ACO with MTSP is enlightened as following steps:

1) Initialize the basic parameters. The number of ants and cities are equal to $N_{w t}+1$. The number of salesmen depends on the current carrying capacity of the cable.

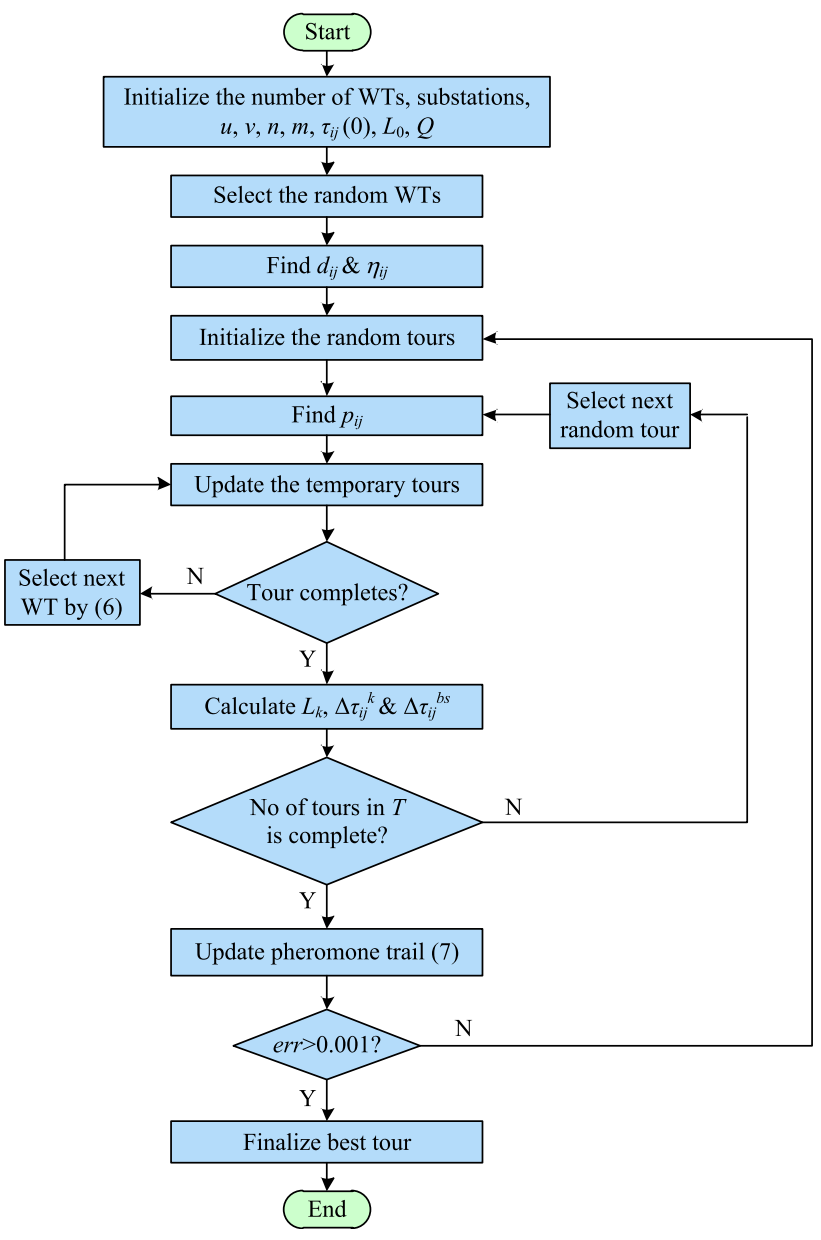

Fig. 1 Flow chart of elitist ACO-MTSP algorithm

2) Select the random WTs for ants or salesmen to start the tour.

3) Calculate the distance matrix $d_{i j}$ between the WTs and visibility matrix $\eta_{i j}$ of WTs by (5).

4) Create a random tour matrix $T$ of WTs. The salesmen will select their random tours for travel.

5) The probability rule (6) decides the salesman to travel $i^{\text {th }}$ WT to next WT in a random tour.

6) Update the tour of salesmen by the strength of pheromone value.

7) After the completion of the tour by salesmen, calculate the length of the each tour.

8) Check whether the number of the specified tours is completed or not. If not select the next random tour in $T$ and repeat the steps 5 to 8 .

9) Update the pheromone trails by (7). Find the minimum length of the tour from the length matrix.

10) Calculate the error value err $=L_{0}-L_{k}$. If $e r r>0.001$ then go to step 4 .

11) Check the condition err $<0.001$, then finalize the optimum tour and length of the tour. 


\section{Model of OSWF}

The modeling of OSWF mainly depends on wake model. The effective performance and power extraction of a wind farm are strongly linked with wake effect. The wake model gives a clear idea of wake effect in wind farm and effective spacing between the WTs.

\subsection{Wake model}

Wakes in wind farms are of two types which are classified based on their distance from the WT. They are near wake and far wake. The distance varies from one to several times of the WT rotor diameter. The far wake models can either be kinematic wake models or field models. In this paper, a kinematic far wake model is taken into consideration. The methodical equations of wake model are explained below.

\subsubsection{Larsen wake model}

The Larsen model was proposed by G.C. Larsen. It is a kinematic model and is formulated using the Prandtl turbulent boundary layer equations. This wake model can give solutions for the mean velocity profile in the wake and the width of the wake. The assumptions are stationary and strong air flow by neglecting wind share [22]. The Larsen model first order equations and solutions are given below.

The wake radius $r_{w}$ is expressed in (8).

$r_{w}=1.7563\left(c_{1}\right)^{\frac{2}{5}}\left(x_{i j}\right)^{\frac{1}{3}}$

where $x_{i j}=C_{T} \frac{A_{o l_{i j}}}{A_{t_{i}}}\left(a+a_{0}\right), C_{T}$ is the thrust coefficient, $A_{o l_{i j}}$ is the area of overlap, and $A_{r}$ is the rotor area. The wake boundary as per (8) is shown in Fig. 2 by a black line.

The velocity deficit in the wake $V_{d_{i j}}$ is given as,

$V_{d_{i j}}=\frac{U_{\infty}}{9} \frac{x_{i j}^{\frac{1}{3}}}{\left(a+a_{0}\right)}+\left[\frac{r^{\frac{3}{2}}}{\sqrt{3 c_{1}^{2} x_{i j}}}+1.344 c_{1}^{-\frac{1}{5}}\right]^{2}$

where $a=y^{*} D(0<\mathrm{y}<15) ; r$ is the rotor radius; $U_{\infty}$ is the undisturbed wind speed; $c_{1}$ is a function of Prandtl mixing length and the rotor position with respect to the applied coordinate system.

$c_{1}=\frac{4.3}{100}\left[\frac{D_{e f f}}{2}\right]^{\frac{5}{2}}\left[C_{T} \frac{A_{o l_{i j}}}{A_{r}} a_{0}\right]^{-\frac{5}{6}}$

The value of $a_{0}$ depends on $D, D_{e f f}$, and $R_{9.5}$. It is indicated in (11).

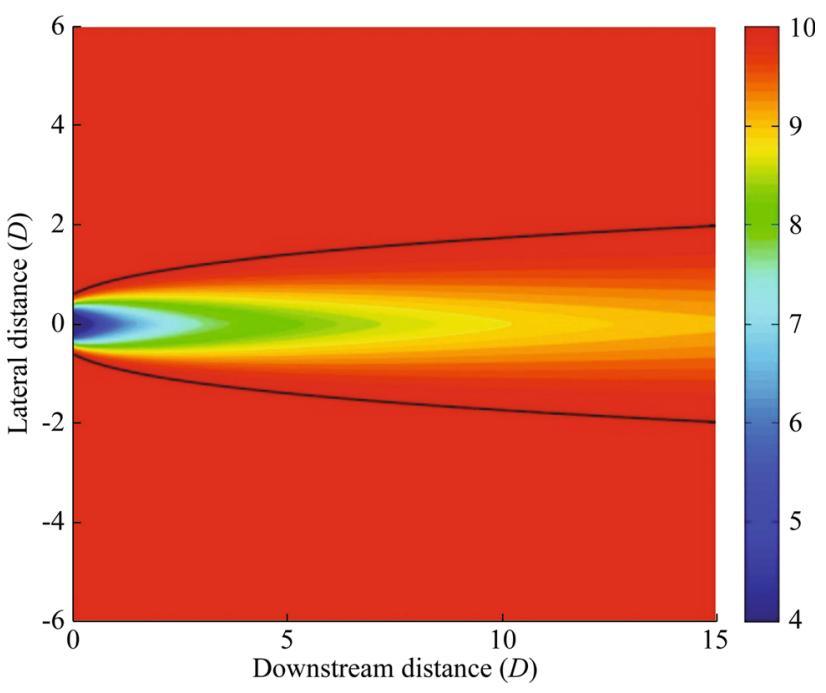

Fig. 2 Larsen model wake formulation

$a_{0}=\frac{9.5 D}{\left(\frac{2 R_{9.5}}{D_{e f f}}\right)^{3}-1}$

where $D$ is rotor diameter and the effective rotor diameter $D_{\text {eff }}$ is expressed as:

$D_{e f f}=D \sqrt{\frac{1+\sqrt{1-C_{T}}}{2 \sqrt{1-C_{T}}}}$

$R_{9.5}$ is the wake radius at a distance of 9.5 times of rotor diameters and it is given as:

$R_{9.5}=0.5\left[R_{n b}+\min \left(H, R_{n b}\right)\right]$

where $H$ is the hub height, $R_{n b}$ is described in (14).

$R_{n b}=\max \left(1.08 D,\left(21.7 T_{a}-0.005\right) D\right)$

where $T_{a}$ is the ambient turbulence intensity. The wake formation behind the WT for $U_{\infty}$ is $10 \mathrm{~m} / \mathrm{s}$ and $T_{a}$ is 0.1 by using Larsen model is shown in Fig. 2 [22].

The total velocity deficit $V_{d}(j)$ at a $j^{\text {th }}$ location WT is affected by wakes. $G(j)$ is the group of WTs affecting the $j^{\text {th }}$ position WT with a wake.

$V_{d}(j)=\sqrt{\sum_{i \in G(j)} V_{d_{i j}}^{2}}$

The wind velocity at $j^{\text {th }}$ WT $U_{j}$ is shown in (16).

$U_{j}=U_{\infty}\left(1-V_{d}(j)\right)$

In the state $s$, a wind farm is experiencing an ambient wind speed in a particular direction. The power produced $P\left(U_{j}(s)\right)$ by the $j^{\text {th }}$ position WT and $U_{j}(s)$ is the wind velocity of $j^{\text {th }}$ WT under state $s$. The power produced by the wind farm is a sum of power produced by $j \in Z$ WTs. In case of various states $s \in S$, the total power produced by the wind 
farm $P_{T}$ is obtained in each state $s$ weighted by the probability of its realization $p_{s}$ [25].

$$
\begin{aligned}
& P_{T}=\sum_{s \in S} p_{s} \sum_{j \in Z} P\left(U_{j}(s)\right) \\
& =\sum_{s \in S} p_{s} \sum_{j \in Z} P\left(U_{s}\left(1-V_{d}(j)\right)\right)
\end{aligned}
$$

The power produced by WT is proportional to $U^{3}$. The assumptions for assessment of the wind farm power production are: $p_{s}$ is constant for every WT in OSWF; WTs rated are same and experience constant wind velocity.

$P_{T} \propto \sum_{j \in Z} P_{j} \approx \sum_{j \in Z}\left(U_{j}\right)^{3}$

\section{Problem formulation}

The formulation is based on the optimization of an offshore wind farm. It mainly deals with the allocation of WTs and substation in the wind farm to reduce the length of interconnection cable between the WTs. The elitist ACO with MTSP approach was used to get the optimal design of offshore wind farm. In (19), $n$ is equal to the sum of a total number of WTs $N_{w t}$ and substations in wind farm $N_{s s}$. Each substation has a set of transformers and it depends on the rating of a wind farm.

$n=N_{w t}+N_{s s}$

The number of inter-array cables is equal to a number of salesmen. Each inter-array cable can connect to a substation and set of WTs. The number of WTs interconnects through the cable $N$ depends on the cable cross-sectional area and current carrying capacity.

The current flow through the inter-array MV submarine cable $I$ from WT is described as below.

$I=\frac{P}{\sqrt{3}}$

where $P$ is the power rating of WT.

$N=\frac{I_{c}}{I}$

where $I_{c}$ is the current carrying capacity of the inter-array submarine cable.

The cost of total inter-array cable $C_{C T}$ is the sum of the interconnecting cable cost given in (22).

$C_{C T}=\sum_{z=1}^{m} C\left(L_{k(z)}\right)=\left(\sum_{z=1}^{m} L_{k(z)}\right) C_{C}$

where $L_{k(z)}=\left(L_{k(1)}, L_{k(2)}, \ldots, L_{k(m)}\right)$ is the length of $m$ interarray cables; $C_{C}$ is the cost of MV submarine cable.

\section{Case study and results}

In this section, small OSWF and large OSWF are taken as reference for the case study. OSWF specifications are as per North Hoyle OSWF and Horns Rev OSWF. The optimization of small and large OSWFs are done by using elitist ACO with MTSP and the analysis is carried out for both with and without wake effect. The wake effect calculations are discussed in subsections. The North Hoyle OSWF is located at Prestatyn in the Irish Sea, United Kingdom. It is consisting of 30 WTs in 6 rows and each row has 5 WTs and its area is $10 \mathrm{~km}^{2}$. The distance between the WTs in a row is $800 \mathrm{~m}$ whereas in a column is $350 \mathrm{~m}$. The rated power of WT is $2 \mathrm{MW}$ and rotor diameter $\mathrm{D}$ is $80 \mathrm{~m}$. The transmission type is MVAC/HVAC with operating voltage level of $33 / 132 \mathrm{kV}$. The inter-array cables interconnect the WTs by 2 radial cables with 15 WTs. The inter-array cable is $33 \mathrm{kV}$ XLPE type AC submarine cable with a cross-sectional area of $185 \mathrm{~mm}^{2}$ and the total length of cable is $18 \mathrm{~km}$. Two export cables are used to interconnect the collector hub and substation. It has a length of 10.781/13.176 km and each cable has $33 \mathrm{kV}$ XLPE type with cross-sectional area of $630 \mathrm{~mm}^{2}$. The Horns Rev OSWF is located at Blavandshuk in the North Sea, Denmark. The specifications of OSWFs are given in Table $1[26,27]$. The parameters of AC inter-array submarine cable are provided in Table 2 [17]. The power curve specifications of OSWFs are shown in Table 3.

\subsection{Computation of wake effect}

The wind sharing at WTs due to wake effect are calculated for two reference OSWFs and shown in Figs. 3 and 4. The existing OSWF data is considered for analysis of wake effect. The spacing between the WTs in a row is $10 D$ and $7 D$ for North Hoyle and Horns Rev OSWFs respectively.

Table 1 Specifications of OSWFs

\begin{tabular}{lll}
\hline Parameters & $\begin{array}{l}\text { North Hoyle } \\
\text { OSWF }\end{array}$ & $\begin{array}{l}\text { Horns Rev } \\
\text { OSWF }\end{array}$ \\
\hline Total capacity & $60 \mathrm{MW}$ & $160 \mathrm{MW}$ \\
Number of WTs & 30 & 80 \\
Annual estimated production & $\begin{array}{l}197.4 \mathrm{GWh} / \\
\text { year }\end{array}$ & $600 \mathrm{GWh} /$ year \\
Area & $10 \mathrm{~km}^{2}$ & $20 \mathrm{~km}^{2}$ \\
Number of rows/WTs & $6 / 5 \mathrm{WTs}$ & $8 / 10 \mathrm{WTs}$ \\
Distance between WTs In rows / & $10 D / 4.375 D$ & $7 D / 7 D$ \\
$\quad$ columns & $18 \mathrm{~km}$ & $63 \mathrm{~km}$ \\
Inter-array cable length & & \\
\hline
\end{tabular}


Table 2 AC submarine cable parameters

\begin{tabular}{llllll}
\hline $\begin{array}{l}\text { Cross-sectional area } \\
\left(\mathrm{mm}^{2}\right)\end{array}$ & $\begin{array}{l}\text { Conductor resistance } \\
(\Omega / \mathrm{km})\end{array}$ & $\begin{array}{l}\text { Cable capacitance } \\
(\mu \mathrm{F} / \mathrm{km})\end{array}$ & $\begin{array}{l}\text { Cable inductance } \\
(\mathrm{mH} / \mathrm{km})\end{array}$ & $\begin{array}{l}\text { Current carrying } \\
\text { capacity }(\mathrm{A})\end{array}$ & $\begin{array}{l}\text { Cable cost }(\mathrm{k} \$ / \\
\mathrm{km})\end{array}$ \\
\hline 70 & 0.3420 & 0.1263 & 0.3865 & 215 & 169.23 \\
120 & 0.1966 & 0.1460 & 0.3637 & 300 & 207.69 \\
185 & 0.1271 & 0.1665 & 0.3456 & 375 & 258.46 \\
240 & 0.0971 & 0.1805 & 0.3365 & 430 & 272.31 \\
\hline
\end{tabular}

Table 3 Power curve specifications of OSWFs

\begin{tabular}{llc}
\hline Parameters & $\begin{array}{l}\text { North Hoyle OSWF } \\
(\mathrm{m} / \mathrm{s})\end{array}$ & $\begin{array}{l}\text { Horns Rev OSWF }(\mathrm{m} / \\
\mathrm{s})\end{array}$ \\
\hline Cut-in wind speed & 3 & 4 \\
Rated wind speed & 13 & 13 \\
$\begin{array}{l}\text { Cut-out wind } \\
\quad \text { speed }\end{array}$ & 25 & 25 \\
$\begin{array}{l}\text { Average wind } \\
\quad \text { speed }\end{array}$ & 8.7 & 9.7 \\
\hline
\end{tabular}

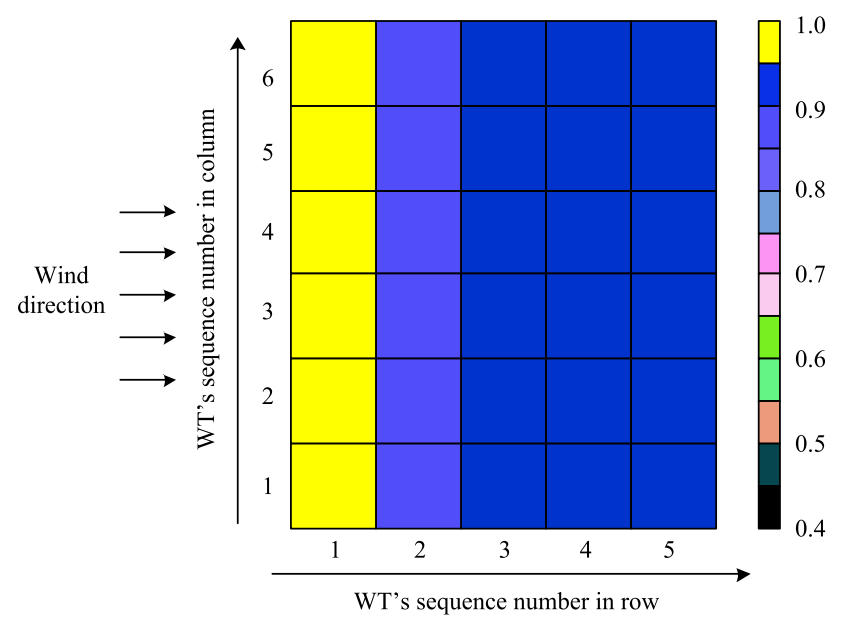

Fig. 3 Wind speed sharing in North Hoyle OSWF at $10 D$

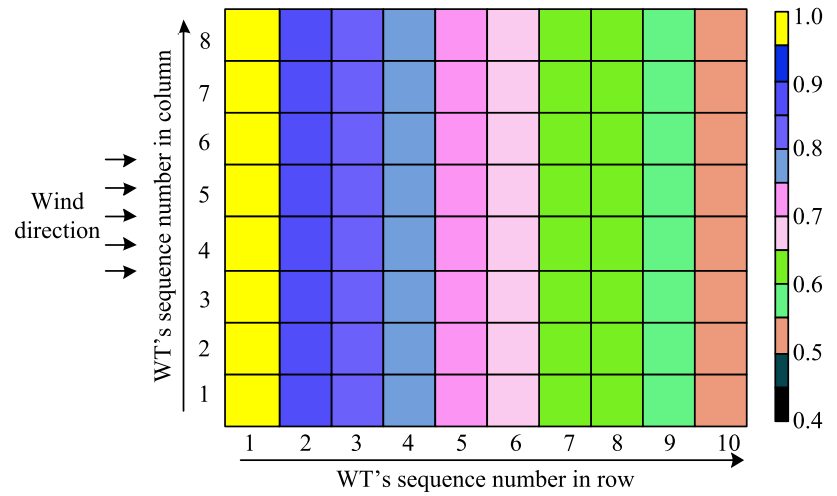

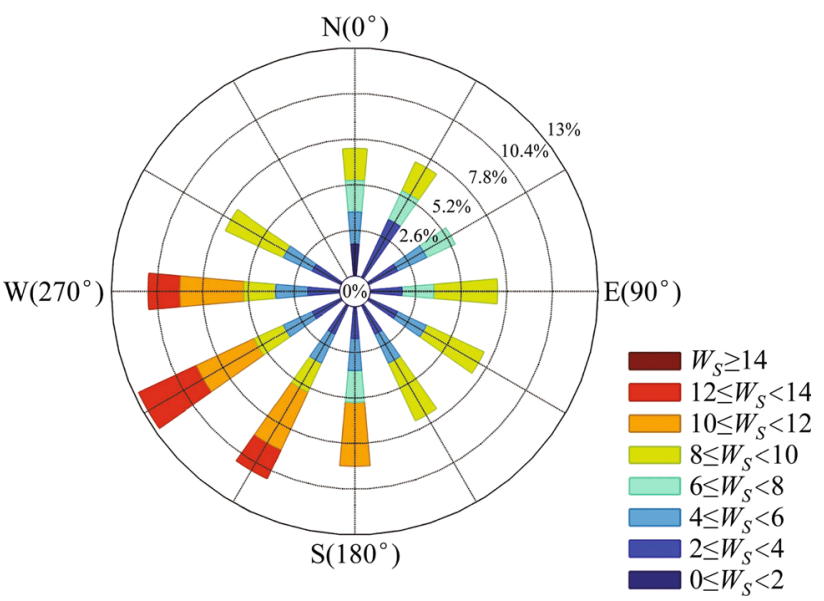

Fig. 5 Wind rose of the North Hoyle OSWF

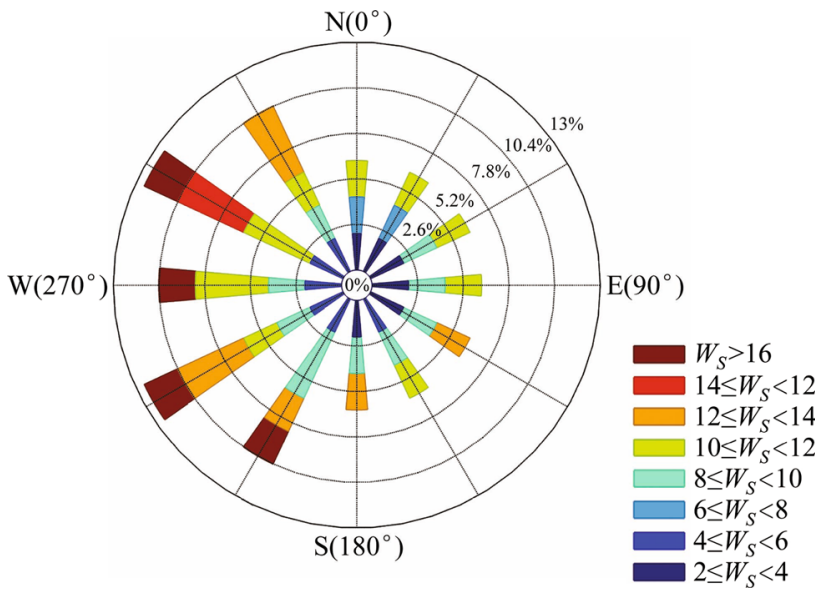

Fig. 6 Wind rose of the Horns Rev OSWF

The wake loss value in percentage is calculated for reference OSWFs. The value of wake loss for North Hoyle OSWF is $7.438 \%$ at $10 \mathrm{D}$ spacing between WTs and Horns Rev OSWF is $27.735 \%$ at $7 D$ spacing between WTs. The wind rose of North Hoyle [28] and Horns Rev [29] OSWFs are represented in Figs. 5 and 6 respectively.

Fig. 4 Wind speed sharing in Horns Rev OSWF at $7 D$ 


\subsection{Optimized design of OSWF}

In this paper, optimized design of OSWF is made with the help of elitist ACO and MTSP technique. The spacing between the WTs in a row is taken as $7 D(560 \mathrm{~m})$ and that of in a column is taken as $4 D(320 \mathrm{~m})$. To achieve an optimized design of OSWF, wake effect and minimum length of inter-array cable are taken into consideration.

\subsubsection{Case 1: without wake effect}

In this case, the wake effect is not taken into consideration and minimum length of inter-array cable is accounted while designing optimal model of OSWF. Figures 7 and 8 show the optimized design of OSWF without wake for North Hoyle (NHWOW) and Horns Rev (HRWOW) OSWFs respectively based on the minimum length of the inter-array cable. The value of wake loss for North Hoyle OSWF is $16.90 \%$ and Horns Rev OSWF is $27.735 \%$ at $7 D$ spacing between WTs.

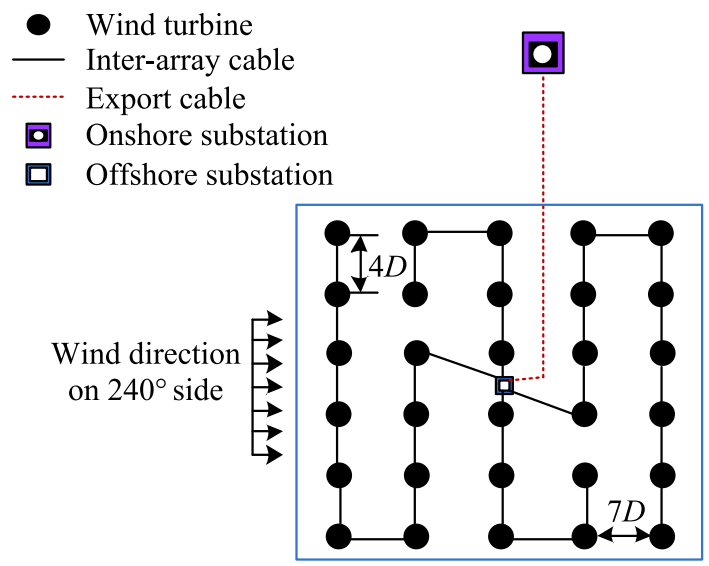

Fig. 7 Design of NHWOW

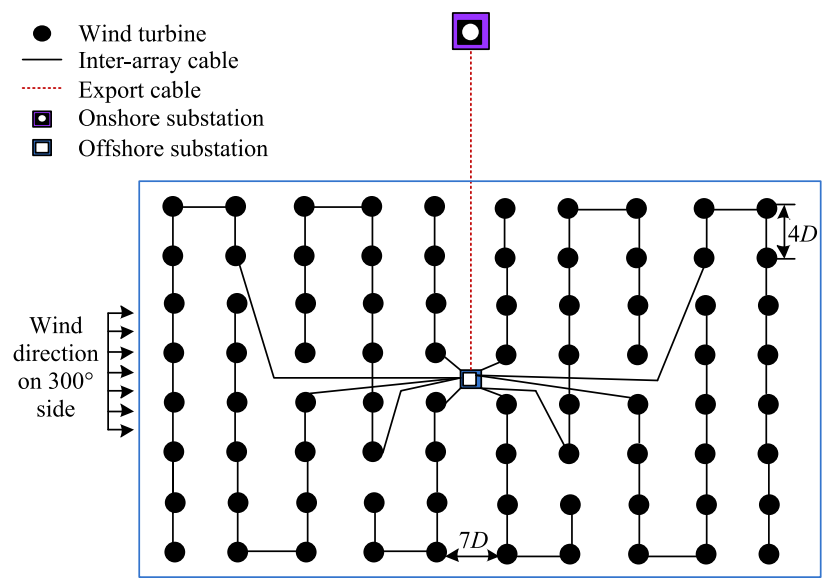

\subsubsection{Case 2: with wake effect}

In this case, the wake effect and minimum length of inter-array cable are considered for the optimal model of OSWF. The placement of WT and spacing between the WTs are chosen from the Larsen wake model as shown in Fig. 2. The amount of wake effect is minimized, if: (1) the $\mathrm{WT}_{12}$ is placed with an angle $\theta_{1}$ with respect to $\mathrm{WT}_{11}$; (2) the $\mathrm{WT}_{13}$ is placed with an angle $\theta_{2}$ and greater than that with respect to $\mathrm{WT}_{11}$. This pattern continues for next columns and it is indicated in Fig. 9. According to an optimal model of WT placement, the wake impact of the primary row WTs is not affected by the consequent row WTs. However, the wake loss of every WT in a row is minimized and average wind velocity receives by the WT of OSWF is improved.

In the wind rose of North Hoyle OSWF, the major part of wind flow is in the direction of $270^{\circ}, 240^{\circ}$, and $210^{\circ}$. The spacing between the WTs placed in a row is $7 D$ which has taken into account for minimization of wake loss for OSWF. The wake loss and average wind velocity of OSWFs are calculated by (15) and (16) respectively. The average wind velocity of the North Hoyle OSWF for the various direction of wind flow is summarized in Table 4 . The wind velocity sharing in North Hoyle OSWF for the direction of wind flow in $270^{\circ}, 240^{\circ}$, and $210^{\circ}$ are represented in Figs. 10, 11, and 12 respectively.

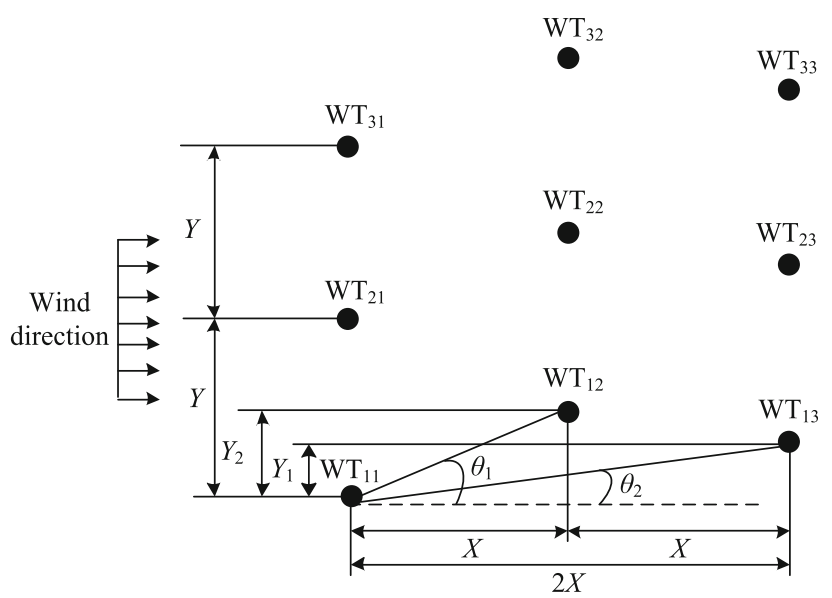

Fig. 9 Optimal design model of WT placement

Table 4 Average wind velocity of North Hoyle OSWF

\begin{tabular}{ll}
\hline Wind flow direction $\left({ }^{\circ}\right)$ & Average wind velocity (p.u.) \\
\hline 270 & 0.992 \\
240 & 0.988 \\
210 & 0.992 \\
\hline
\end{tabular}

Fig. 8 Design of HRWOW 


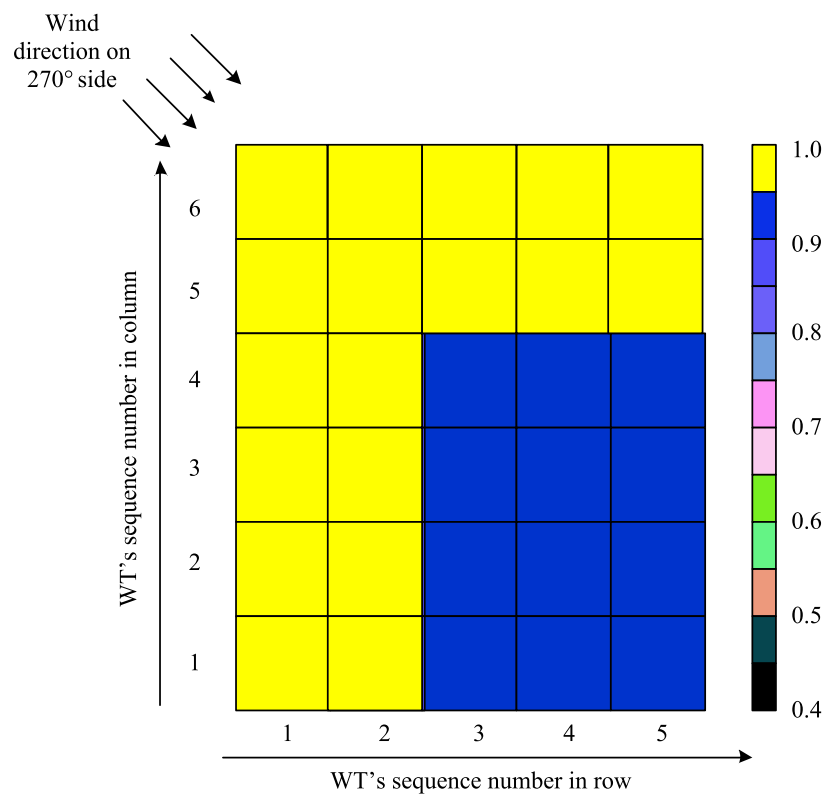

Fig. 10 Wind velocity sharing in North Hoyle OSWF for direction of wind flow in $270^{\circ}$

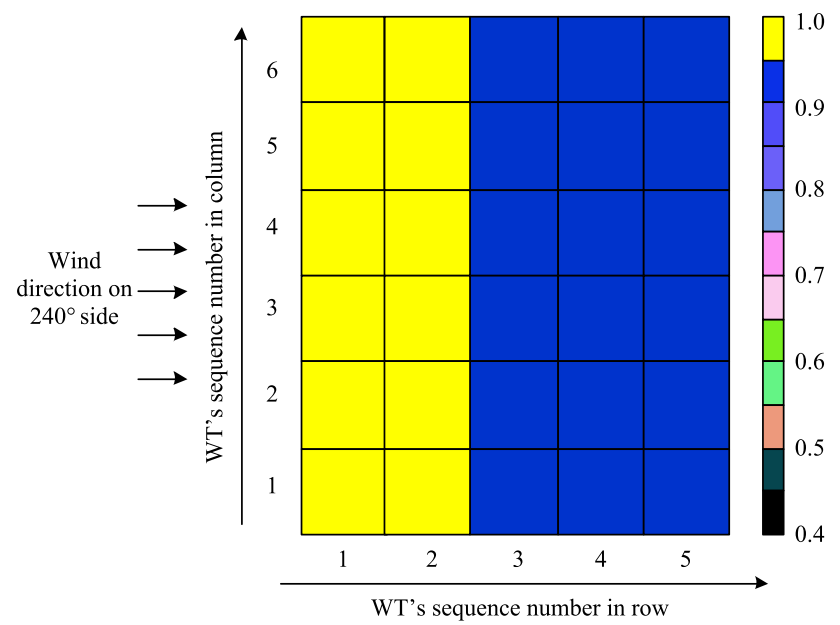

Fig. 11 Wind velocity sharing in North Hoyle OSWF for direction of wind flow in $240^{\circ}$

In the wind rose of Horns Rev OSWF, the major part of wind flow is in the direction of $330^{\circ}, 300^{\circ}$, and $240^{\circ}$. The average wind velocity of the Horns Rev OSWF for the various direction of wind flow is summarized in Table 5. The wind velocity sharing in Horns Rev OSWF for the direction of wind flow in $330^{\circ}, 300^{\circ}$, and $240^{\circ}$ are represented in Figs. 13, 14, 15 respectively.

Figures 16 and 17 show the optimal design of OSWF with a wake for North Hoyle (NHWW) and Horns Rev (HRWW) OSWFs respectively based on the minimum length of an inter-array cable. The wake loss was minimized in both the cases at $7 D$ spacing between WTs.

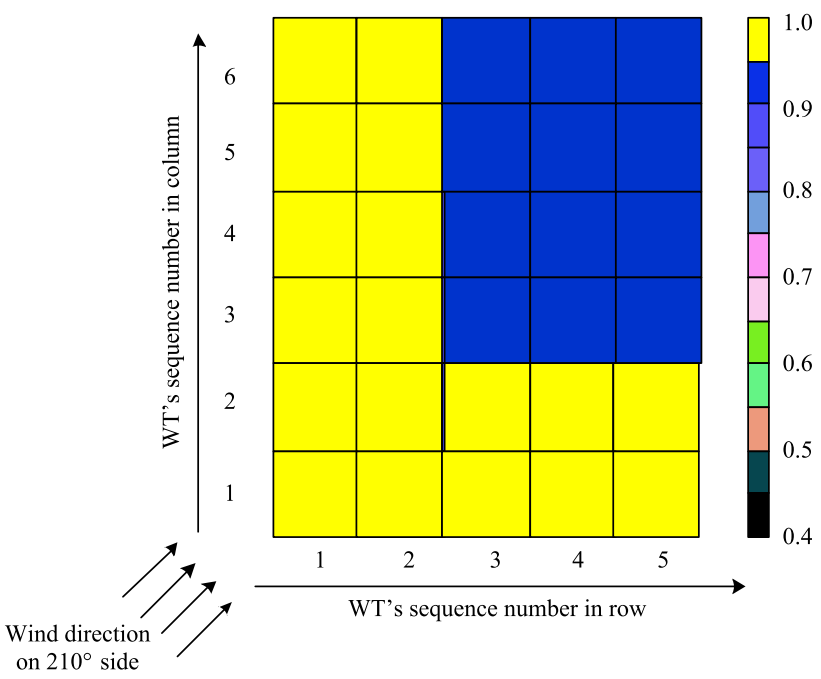

Fig. 12 Wind velocity sharing in North Hoyle OSWF for direction of wind flow in $210^{\circ}$

Table 5 Average wind velocity of Horns Rev OSWF

\begin{tabular}{ll}
\hline Wind flow direction $\left({ }^{\circ}\right)$ & Average wind velocity (p.u.) \\
\hline 330 & 0.988 \\
300 & 0.984 \\
240 & 0.988 \\
\hline
\end{tabular}

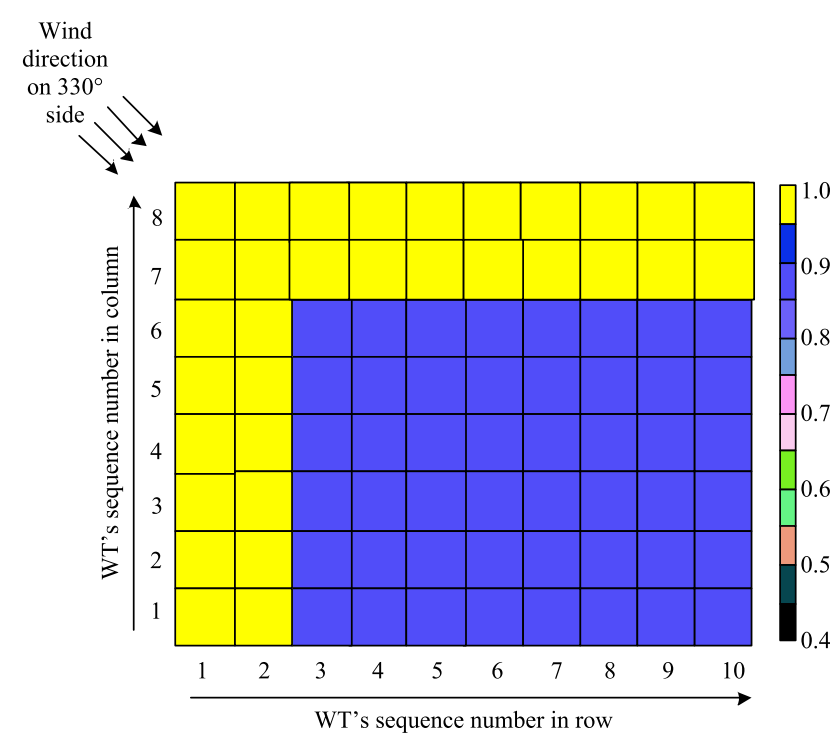

Fig. 13 Wind velocity sharing in Horns Rev OSWF for direction of wind flow in $330^{\circ}$

The power production of OSWF is affected by the value of wake loss in OSWF and it is calculated by using (18). The power production of individual WT $\left(P_{\text {base }}\right)$ in NH and HR OSWFs are $1.2 \mathrm{MW}$ at average wind speed $8.7 \mathrm{~m} / \mathrm{s}$ 


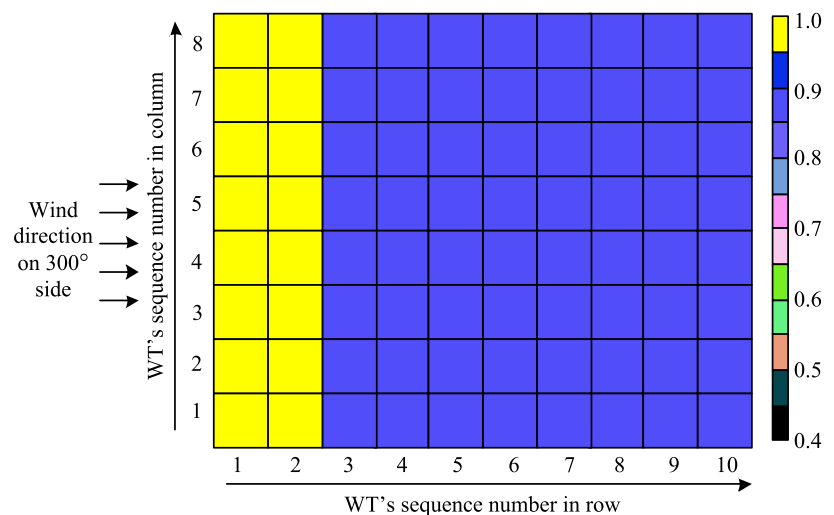

Fig. 14 Wind velocity sharing in Horns Rev OSWF for direction of wind flow in $300^{\circ}$

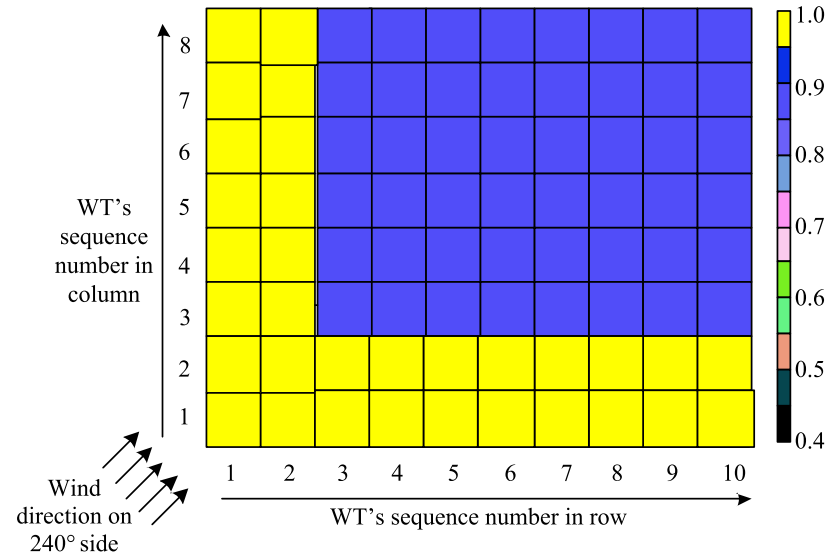

Fig. 15 Wind velocity sharing in Horns Rev OSWF for direction of wind flow in $240^{\circ}$

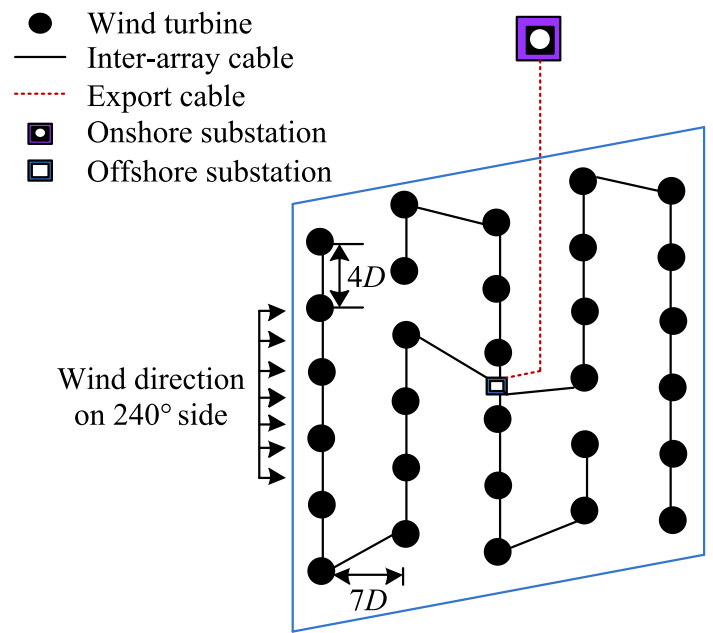

Fig. 16 Design of NHWW for Larsen model

and $1.7 \mathrm{MW}$ at average wind speed $9.7 \mathrm{~m} / \mathrm{s}$ respectively. The total base power value of NH and HR OSWF are 36 and $136 \mathrm{MW}$ respectively. The approximate power

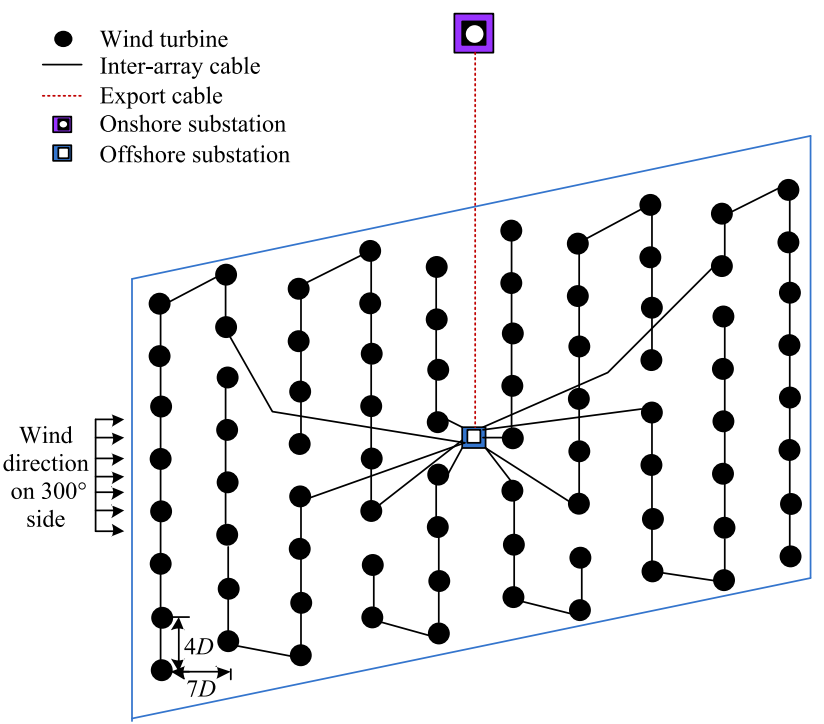

Fig. 17 Design of HRWW for Larsen model

production $P_{\text {aprox }}$ is indicated in per units (p.u.). In case of lower wake loss of OSWF, the WT can experience more healthy wind. It reflects higher power production in OSWF. The different cross-sectional area of inter-array cables has taken for case study. It includes 120,185 , and $240 \mathrm{~mm}^{2}$. The value of $N$ for various inter-array cables is shown in Table 6.

The NHWW and HRWW designs are developed with help of Larsen and Jensen wake model. The inter-array cable length, cost, average wind velocity $U_{\text {avg }}$, and $P_{\text {aprox }}$ of NHWW for Larsen and Jensen wake models are compared in Tables 7 and 8 respectively.

The inter-array cable length, cost, $U_{\text {avg }}$, and $P_{\text {aprox }}$ of HRWW for Larsen and Jensen wake models are compared in Tables 9 and 10 respectively.

The results of NHWW and HRWW concludes the $240 \mathrm{~mm}^{2}$ cross-sectional area cable is best in terms of cable length and the $120 \mathrm{~mm}^{2}$ cross-sectional area cable is best in terms of cable cost. The Larsen and Jensen model based OSWF designs are producing the same amount of $P_{\text {aprox }}$ and WTs have experienced the good amount of $U_{\text {avg }}$. The statistical analysis in terms of average wind velocity $U_{\text {avg }}$ and approximate power production $P_{\text {aprox }}$ of OSWF for various distances between the WTs are investigated. The assumption is primary row WTs are experienced the

Table 6 Value of $N$ for various inter-array cables

\begin{tabular}{lll}
\hline $\begin{array}{l}\text { Cross-sectional area } \\
\left(\mathrm{mm}^{2}\right)\end{array}$ & $\begin{array}{l}\text { Approximate } \\
\text { value of } N\end{array}$ & $\begin{array}{l}\text { Number of WTs taken } \\
\text { into account }\end{array}$ \\
\hline 120 & 8 & 8 \\
185 & 11 & 10 \\
240 & 13 & 12 \\
\hline
\end{tabular}


Table 7 Results summary of NH OSWF designs for Larsen model

\begin{tabular}{|c|c|c|c|c|c|c|}
\hline OSWF & $\begin{array}{l}\text { Cross-sectional area } \\
\left(\mathrm{mm}^{2}\right)\end{array}$ & $\begin{array}{l}\text { Spacing between WTs in } \\
\text { rows/columns }\end{array}$ & $\begin{array}{l}\text { Inter-array cable length } \\
(\mathrm{km})\end{array}$ & $\begin{array}{l}\text { Inter-array cable cost } \\
(\mathrm{k} \$ / \mathrm{km})\end{array}$ & $\begin{array}{l}U_{\text {avg }} \\
\text { (p.u.) }\end{array}$ & $\begin{array}{l}P_{\text {aprox }} \\
\text { (p.u.) }\end{array}$ \\
\hline $\mathrm{NH}$ & 185 & $10 D / 4.375 D$ & 18.000 & 4652.30 & 0.926 & 0.793 \\
\hline NHWOW & 185 & $7 D / 4 D$ & 10.765 & 2782.30 & 0.831 & 0.574 \\
\hline \multirow[t]{3}{*}{ NHWW } & 120 & $7 D / 4 D$ & 11.630 & 2415.44 & 0.988 & 0.964 \\
\hline & 185 & $7 D / 4 D$ & 10.832 & 2799.60 & 0.988 & 0.964 \\
\hline & 240 & $7 D / 4 D$ & 11.328 & 3084.70 & 0.988 & 0.964 \\
\hline
\end{tabular}

Table 8 Results summary of NH OSWF designs for Jensen model

\begin{tabular}{lllllll}
\hline OSWF & $\begin{array}{l}\text { Cross-sectional area } \\
\left(\mathrm{mm}^{2}\right)\end{array}$ & $\begin{array}{l}\text { Spacing between WTs in } \\
\text { rows/columns }\end{array}$ & $\begin{array}{l}\text { Inter-array cable length } \\
(\mathrm{km})\end{array}$ & $\begin{array}{l}\text { Inter-array cable cost } \\
(\mathrm{k} / \mathrm{km})\end{array}$ & $\begin{array}{l}U_{\text {avg }} \\
(\mathrm{p} . \mathrm{u} .)\end{array}$ & $\begin{array}{c}P_{\text {aprox }} \\
(\mathrm{p} . \mathrm{u})\end{array}$ \\
\hline NHWW & 120 & $7 D / 4 D$ & 11.542 & 2397.2 & 0.988 & 0.964 \\
& 185 & $7 D / 4 D$ & 10.893 & 2815.4 & 0.988 & 0.964 \\
& 240 & $7 D / 4 D$ & 11.338 & 3087.5 & 0.988 & 0.964 \\
\hline
\end{tabular}

Table 9 Results summary of HR OSWF designs for Larsen model

\begin{tabular}{|c|c|c|c|c|c|c|}
\hline OSWF & $\begin{array}{l}\text { Cross-sectional area } \\
\left(\mathrm{mm}^{2}\right)\end{array}$ & $\begin{array}{l}\text { Spacing between WTs in } \\
\text { rows/columns }\end{array}$ & $\begin{array}{l}\text { Inter-array cable length } \\
(\mathrm{km})\end{array}$ & $\begin{array}{l}\text { Inter-array cable cost } \\
(\mathrm{k} \$ / \mathrm{km})\end{array}$ & $\begin{array}{l}U_{\text {avg }} \\
\text { (p.u.) }\end{array}$ & $\begin{array}{l}P_{\text {aprox }} \\
\text { (p.u.) }\end{array}$ \\
\hline HR & 185 & $7 D / 7 D$ & 63.000 & 16283 & 0.723 & 0.384 \\
\hline HRWOW & 185 & $7 D / 4 D$ & 35.706 & 9228.6 & 0.723 & 0.384 \\
\hline \multirow[t]{3}{*}{ HRWW } & 120 & $7 D / 4 D$ & 39.538 & 8211.7 & 0.984 & 0.953 \\
\hline & 185 & $7 D / 4 D$ & 35.287 & 9120.3 & 0.984 & 0.953 \\
\hline & 240 & $7 D / 4 D$ & 34.607 & 9423.8 & 0.984 & 0.953 \\
\hline
\end{tabular}

Table 10 Results summary of HR OSWF designs for Jensen model

\begin{tabular}{|c|c|c|c|c|c|c|}
\hline OSWF & $\begin{array}{l}\text { Cross-sectional area } \\
\left(\mathrm{mm}^{2}\right)\end{array}$ & $\begin{array}{l}\text { Spacing between WTs in } \\
\text { rows/columns }\end{array}$ & $\begin{array}{l}\text { Inter-array cable length } \\
(\mathrm{km})\end{array}$ & $\begin{array}{l}\text { Inter-array cable cost } \\
(\mathrm{k} \$ / \mathrm{km})\end{array}$ & $\begin{array}{l}U_{\text {avg }} \\
\text { (p.u.) }\end{array}$ & $\begin{array}{l}P_{\text {aprox }} \\
\text { (p.u.) }\end{array}$ \\
\hline \multirow[t]{3}{*}{ HRWW } & 120 & $7 D / 4 D$ & 38.864 & 8071.7 & 0.984 & 0.953 \\
\hline & 185 & $7 D / 4 D$ & 35.046 & 9058.0 & 0.984 & 0.953 \\
\hline & 240 & $7 D / 4 D$ & 34.677 & 9442.9 & 0.984 & 0.953 \\
\hline
\end{tabular}

1 p.u. undisturbed healthy and unidirectional wind flow. The graphical representations of the $U_{\text {avg }}$ and $P_{\text {aprox }}$ for the North Hoyle OSWF are shown in Figs. 18 and 19 respectively.

The observations of the Fig. 18 are: (1) the $U_{\text {avg }}$ of NHWOW is increasing slowly with the distance $D$ and WTs may experience $100 \%$ healthy wind flow after the $15 D$ spacing; (2) the $U_{\text {avg }}$ of NHWW is reached $98.8 \%$ at $6 D$ and $100 \%$ at $7 D$ spacing. The $P_{\text {aprox }}$ of (1) NHWOW is
0.95 p.u. at $15 D$ and (2) NHWW is 0.965 and 1 p.u. at $6 D$ and $7 D$ respectively. The graphical representation of the $U_{\text {avg }}$ and $P_{\text {aprox }}$ of the Horns Rev OSWF are shown in Figs. 20 and 21 respectively.

The observations of Fig. 20 are: (1) the $U_{\text {avg }}$ of HRWOW is increasing slowly with the distance $D$ and WTs may experience $99 \%$ healthy wind flow at $15 D$ spacing; (2) the $U_{a v g}$ of HRWW is reached $98.4 \%$ at $6 D$ and $100 \%$ at 


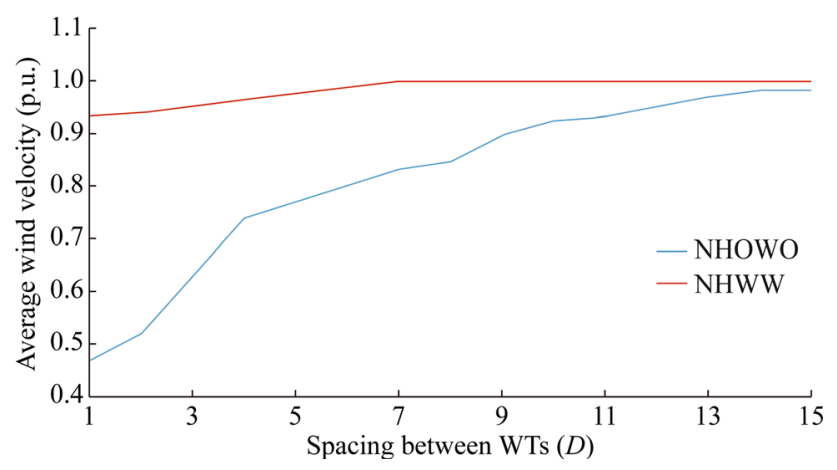

Fig. $18 U_{\text {avg }}$ for North Hoyle OSWF

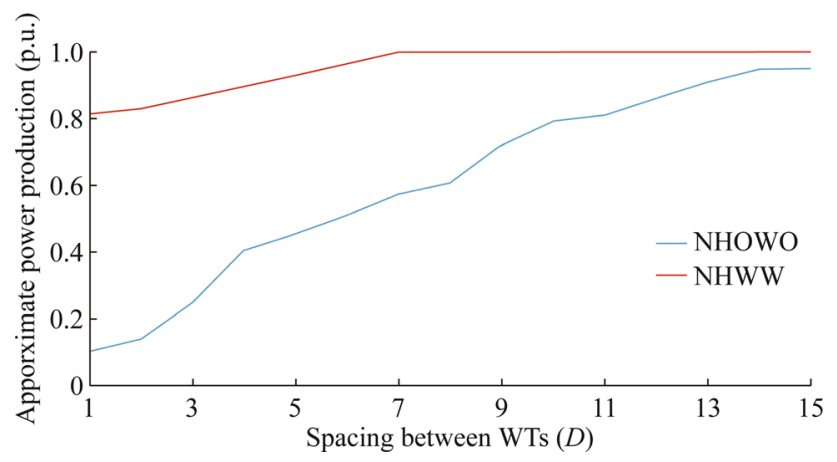

Fig. $19 P_{\text {aprox }}$ for North Hoyle OSWF

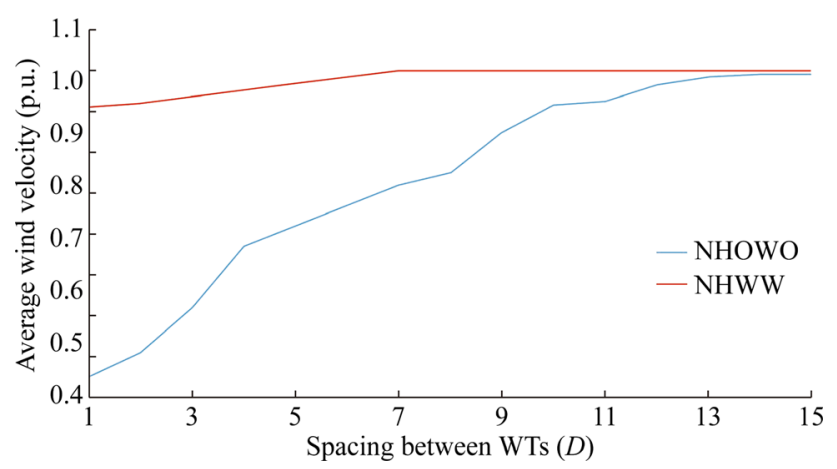

Fig. $20 U_{\text {avg }}$ for Horns Rev OSWF

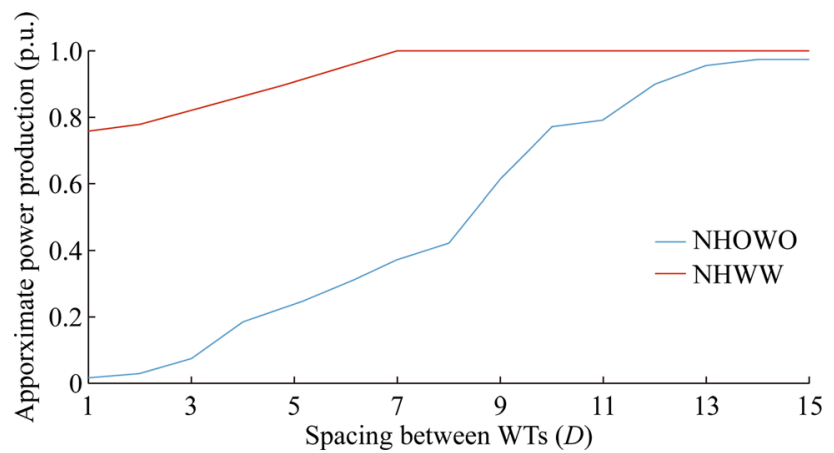

$7 D$ spacing. The $P_{\text {aprox }}$ of HRWOW is 0.97 p.u. at $15 D$ and HRWW is 0.95 and 1 p.u. at $6 D$ and $7 D$ respectively.

\section{Conclusion}

Application of elitist ACO with MTSP approach to get an optimized design of OSWF is explained in this paper. The combined approach is explained with the help of flow chart. The NHWOW and NHWW are based on North Hoyle OSWF. The HRWOW and HRWW are based on Horns Rev OSWF. The inter-array cable length and cost of OSWF are reduced due to optimal design. The inter-array cable cost of NHWW is $60.17 \%$ of North Hoyle design whereas the cost of HRWW is $56.01 \%$ of Horns Rev design. The wake loss of wind farm is minimized in NHWW and HRWW as compared to other designs. This optimized approach has improved the approximate power production of OSWFs with the consideration of wake. This paper concludes that NHWW and HRWW give better results on the basis of minimum length of inter-array cable and wake loss.

Open Access This article is distributed under the terms of the Creative Commons Attribution 4.0 International License (http:// creativecommons.org/licenses/by/4.0/), which permits unrestricted use, distribution, and reproduction in any medium, provided you give appropriate credit to the original author(s) and the source, provide a link to the Creative Commons license, and indicate if changes were made.

\section{References}

[1] Prada MD, Igualada L, Corchero C et al (2015) Hybrid AC-DC offshore wind power plant topology: optimal design. IEEE Trans Power Syst 30(4):1868-1876

[2] Srikakulapu R, Vinatha U (2015) Electrical collector topologies for offshore wind power plants: a survey. In: Proceedings of 2015 IEEE 10th international conference on industrial and information systems (ICIIS), Peradeniya, Sri Lanka, 18-20 December 2015, 6 pp

[3] Nandigam M, Dhali SK (2008) Optimal design of an offshore wind farm layout. In: Proceedings of international symposium on power electronics, electrical drives, automation and motion, Ischia, Italy, 11-13 June 2008, 5 pp

[4] Dahmani O, Bourguet S, Machmoum M et al (2015) Optimization of the connection topology of an offshore wind farm network. IEEE Syst J 9(4):1519-1528

[5] Gonzalez-Longatt FM, Wall P, Regulski P et al (2012) Optimal electric network design for a large offshore wind farm based on a modified genetic algorithm approach. IEEE Syst J $6(1): 164-172$

[6] Gonzalez-Longatt FM (2013) Optimal offshore wind farms collector design based on the multiple travelling salesman problem and genetic algorithm. In: Proceedings of IEEE Grenoble PowerTech, Grenoble, France, 16-20 June 2013, 6 pp

Fig. $21 P_{\text {aprox }}$ for Horns Rev OSWF 
[7] Gonz JS, Pay MB, Santos JR et al (2013) A new and efficient method for optimal design of large offshore wind power plants. IEEE Trans Power Syst 28(3):3075-3084

[8] Lumbreras S, Ramos A (2013) Optimal design of the electrical layout of an offshore wind farm applying decomposition strategies. IEEE Trans Power Syst 28(2):1434-1441

[9] Chen Y, Dong Z, Meng K et al (2013) A novel technique for the optimal design of offshore wind farm electrical layout. J Modern Power Syst Clean Energy 1(3):258-263

[10] Dutta S, Overbye TJ (2012) Optimal wind farm collector system topology design considering total trenching length. IEEE Trans Sustain Energy 3(3):339-348

[11] Hou P, Hu W, Soltani M et al (2015) Optimized placement of wind turbines in large-scale offshore wind farm using particle swarm optimization algorithm. IEEE Trans Sustain Energy 6(4): 1272-1282

[12] Hou P, Hu W, Chen C et al (2017) Overall optimization for offshore wind farm electrical system. Wind Energy 20(6):1017-1032

[13] Hou P, Hu W, Soltani M et al (2017) Combined optimization for offshore wind turbine micro siting. Appl Energy 189:271-282

[14] Joanna B, Lysgaard J (2015) The offshore wind farm array cable layout problem: a planar open vehicle routing problem. J Oper Res Soc 66(3):360-368

[15] Wu YK, Lee CY, Chen CR et al (2014) Optimization of the wind turbine layout and transmission system planning for a large-scale offshore windfarm by AI technolgy. IEEE Trans Ind Appl 50(3):2071-2080

[16] Pillai AC, Chick J, Johanning L et al (2015) Offshore wind farm electrical cable layout optimization. Eng Optim 47(12):1689-1708

[17] Chen Y, Dong ZY, Meng K et al (2016) Collector system layout optimization framework for large-scale offshore wind farms. IEEE Trans Sustain Energy 7(4):1398-1407

[18] Hou P, Hu W, Chen Z et al (2016) Optimisation for offshore wind farm cable connection layout using adaptive particle swarm optimisation minimum spanning tree method. IET Renew Power Gener 10(5):694-702

[19] Hou P, Hu W, Zhang B et al (2016) Optimised power dispatch strategy for offshore wind farms. IET Renew Power Gener 10(3):399-409

[20] Hou P, Hu W, Chen C et al (2016) Optimisation of offshore wind farm cable connection layout considering levelised production cost using dynamic minimum spanning tree algorithm. IET Renew Power Gener 10(2):175-183

[21] Barthelmie RJ, Hansen KS, Pryor SC et al (2013) Meteorological controls on wind turbine wakes. Proc IEEE 101(4):1010-1019
[22] Renkema DJ (2007) Validation of wind turbine wake models. Delft University of Technology, Delft

[23] Dorigo M, Birattari M, Stutzle T (2006) Ant colony optimization. The MIT press, Cambridge

[24] Colorni A, Dorigo M, Maniezzo V (1992) Distributed optimization by ant colonies. In: Proceedings of European conference on artificial life, Vienna, Austria, 3-7 August 1992, 9 pp

[25] Samorani M (2013) The wind farm layout optimization problem. Springer, Germany, pp 21-38

[26] North hoyle offshore wind farm. http://www.4coffshore.com/ windfarms/north-hoyle-united-kingdom-uk16.html

[27] Horns rev offshore wind farm, http://www.4coffshore.com/ windfarms/horns-rev-1-denmark-dk3.html

[28] BERR (2007) Capital grant scheme for the North Hoyle offshore wind farm annual report: July 2006-June 2007. Power Renewables Limited

[29] Hansen KS, Barthelmie RJ, Jensen LE et al (2012) The impact of turbulence intensity and atmospheric stability on power deficits due to wind turbine wakes at Horns Rev wind farm. Wind Energy 15(1):183-196

Ramu SRIKAKULAPU received his B.Tech degree from VIIT Visakhapatnam, JNTU Hyderabad, India in 2008, M.Tech degree from NIT Kurukshetra, India in 2012, all in Electrical Engineering. $\mathrm{He}$ is now a research scholar at Department of Electrical and Electronics Engineering, NITK Surathkal, India. His research interest includes grid integration of renewable energy sources, optimal controllers for HVDC transmission, and optimization algorithms and its application to renewable energy sources.

Vinatha $\mathbf{U}$ received her B.Tech and M.Tech degrees from KREC Surathkal, Mangalore University, India respectively in 1986 and 1992 and Ph.D degree from NITK Surathkal, India in 2013, all in Electrical Engineering. She is now an associate professor at Department of Electrical and Electronics Engineering, NITK Surathkal. Her research interest includes power electronics and drives, power electronic converters in renewable systems, multilevel inverters and wave energy conversion system. 